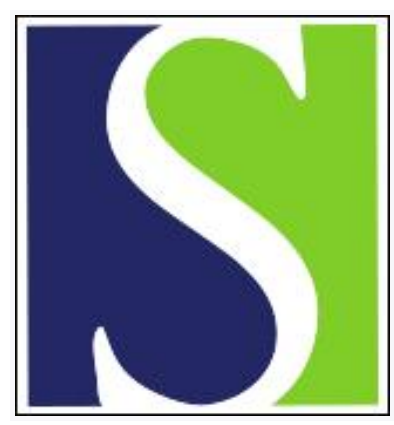

Scand J Work Environ Health 2012;38(1):1-3

https://doi.org/10.5271/sjweh.3261

Published online: 14 Nov 2011, Issue date: Jan 2012

Noise and ischemic heart disease

by Bonde JP, Kolstad HA

Affiliation: Department of Occupational and Environmental Medicine, Bispebjerg Hospital, University of Copenhagen, Denmark. jpb@bbh.regionh.dk

Refers to the following texts of the Journal: 2005;31(4):291-299 2006;32(6):431-442 2010;36(2):96-108 2012;38(1):19-26

Key terms: angina; cardiac function; cardiovascular disease; editorial; ischemic heart disease; mortality; noise; noise exposure; occupational noise

This article in PubMed: www.ncbi.nlm.nih.gov/pubmed/22083561 


\section{Noise and ischemic heart disease}

The incidence and mortality of ischemic heart disease (IHD) declined dramatically in affluent countries from the early 1980s until at least the mid 1990s (1). This change in occurrence is ascribed to improved lifestyle factors, primarily a decrease in smoking and an increase in leisure-time exercise, and better care of the coronary heart patient (2). The downward shift in incidence has taken place in spite of the escalating obesity epidemic and a high prevalence of occupational and environmental noise exposure $(3,4)$. IHD is still the leading cause of death, thus, as some preventive measures become fully implemented, the identification of novel risk factors becomes more important. In the field of occupational and environmental health, there are at least three widespread exposures that are not entirely recognized as causal risk factors by influential opinion-makers such as the American Heart Association (5). In addition to noise (6) and shift work (7), these also include psychosocial and organizational factors (8).

In this issue of the Scandinavian Journal of Work, Environment and Health, Poul Suadicani and coauthors add a new study (9) to the short list of four published follow-up studies addressing the risk of IHD in relation to occupational noise exposure $(6,10-12)$. They report a follow-up through 16 years of mortality due to IHD among almost 3000 men from Copenhagen and find no indication of increased risk according to self-reported noise, either before or after adjustment for classical cardiovascular risk factors. This result is consistent with an Israeli study that did not show increased noise-related risk of IHD (but rather total mortality) (12) and a Finnish census study showing fairly weak associations (11). But the result is not consistent with the increased IHD mortality observed in a large study of Canadian lumber-mill workers (10). Although exposure levels to noise in that study were far above the average exposure levels in the Danish industry (3), the increased risk was not limited to high exposure levels exceeding 90-95 dB(A). Thus the discrepant results are not explained by differences in exposure levels. The findings of the Suadicani et al study seem also contradictory to a long-term follow up of industrially employed men in Helsinki, where occupational noise was associated with an increased risk of IHD that persisted even when the workers had passed the age of retirement (6). Is residual confounding due to insufficient control for social class at stake in the Helsinki and lumber mill studies or are crude exposure assessments attenuating true effects in the Copenhagen study?

Unfortunately we do not find an answer among the mounting evidence from studies of cardiovascular risk factors related to environmental noise - mainly road and air traffic noise (4). Although community sound levels are orders of magnitude lower than industrial levels, contrary to occupational exposure, environmental exposure affects sleeping hours and resting time off work. Furthermore, the total number of exposed hours is higher, ear protection is not an option, and transportation noise causes more annoyance than industrial noise (13). The last point might be important if sound annoyance (noise) rather than sound pressure were harmful and if psychological discomfort reinforced the acute physiological stress response that noise exposure evidently elicits (14).

On the other hand, experimental as well as field studies of human exposure to noise show marked adaptation of the physiological stress response with continuous or repeated exposure - but perhaps not without ill-health effects in the long run (15). Accordingly, noise in both the workplace and environment represents different modalities, which may be associated with different risk profiles. Although several cross-sectional studies provide some evidence that road traffic and airport noise is related to small 
increments in ambulant blood pressure, the few available follow-up studies of IHD do not indicate an increased risk $(16,17)$.

Knowledge on the extra-auditive effects of noise is of interest from a different perspective. Over decades, research on the risk of IHD in relation to job strain and other work-related psychosocial factors has not convinced the entire scientific community that observed associations are likely of a causal nature (18-20). A major methodological obstacle is the lack of independent measures of exposure $(19,21)$. In this context, it is of interest that some of the suggested mechanisms responsible for cardiovascular effects of psychosocial aspects of life are similar to mechanisms suggested for cardiovascular effects of noise namely a prolonged unspecific biological stress response in terms of activation of the autonomic nervous system and neuroendocrine pathways $(22,23)$. In fact, the acute physiologic effect of psychosocial factors and noise are much alike (14). Thus noise can be considered an objective stressor and studies of noise may provide insight into the long-term effects of sustained activation of the physiologic stress response, if such effects exist. It should be acknowledged, however, that the empirical evidence for a long-term, low-dose activation of the autonomous nervous system and the hypothalamic-pituitary-adrenal axis by psychosocial factors and noise is limited (24-26).

Although the findings of the Suadicani et al study in this issue of the Journal are reassuring, it seems far too early to dismiss ischemic heart disease morbidity and mortality as a long-term consequence of noise even at environmental exposure levels. Several cohorts with good data on exposure, outcomes, extraneous determinants, as well as possible individual effect modifiers will hopefully provide new insight and inform the public and decision-makers in occupational and public health.

\section{References}

1. Tunstall-Pedoe H, Kuulasmaa K, Mahonen M, Tolonen H, Ruokokoski E, Amouyel P. Contribution of trends in survival and coronary-event rates to changes in coronary heart disease mortality: 10-year results from 37 WHO MONICA project populations. Monitoring trends and determinants in cardiovascular disease. Lancet. 1999;353:1547-57. http://dx.doi. org/10.1016/S0140-6736(99)04021-0.

2. Kabir Z, Bennett K, Shelley E, Unal B, Critchley JA, Capewell S. Comparing primary prevention with secondary prevention to explain decreasing coronary heart disease death rates in Ireland, 1985-2000. BMC Public Health. 2007;7:117 http://dx.doi.org/10.1186/1471-2458-7-117.

3. Kock S, Andersen T, Kolstad HA, Kofoed-Nielsen B, Wiesler F, Bonde JP. Surveillance of noise exposure in the Danish workplace: a baseline survey. Occup Environ Med. 2004; 61:838-43. http://dx.doi.org/10.1136/oem.2004.012757.

4. Jarup L, Babisch W, Houthuijs D, Pershagen G, Katsouyanni K, Cadum E, Dudley ML, Savigny P, Seiffert I, Swart W, et al. Hypertension and exposure to noise near airports: the HYENA study. Environ Health Perspect. 2008;116:329-33. http:// dx.doi.org/10.1289/ehp.10775.

5. Unal B, Critchley JA, Capewell S. Explaining the decline in coronary heart disease mortality in England and Wales between 1981 and 2000. Circulation 2004;109:1101-7. http://dx.doi.org/10.1161/01.CIR.0000118498.35499.B2.

6. Virkkunen H, Kauppinen T, Tenkanen L. Long-term effect of occupational noise on the risk of coronary heart disease. Scand J Work Environ Health. 2005;31:291-9.

7. Puttonen S, Harma M, Hublin C. Shift work and cardiovascular disease - pathways from circadian stress to morbidity. Scand J Work Environ Health 2010;36:96-108.

8. Kivimaki M, Virtanen M, Elovainio M, Kouvonen A, Vaananen A, Vahtera J. Work stress in the etiology of coronary heart disease--a meta-analysis. Scand J Work Environ Health. 2006;32:431-42.

9. Suadicani P, Hein HO, Gyntelberg F. Occupational noise exposure, social class, and risk of ischemic heart disease and allcause mortality - a 16-year follow-up in the Copenhagen Male Study. Scand J Work Environ Health. 2012;38(1):19-26.

10. Davies HW, Teschke K, Kennedy SM, Hodgson MR, Hertzman C, Demers PA. Occupational exposure to noise and mortality from acute myocardial infarction. Epidemiology. 2005;16:25-32. http://dx.doi.org/10.1097/01.ede.0000147121.13399.bf.

11. Virtanen SV, Notkola V. Socioeconomic inequalities in cardiovascular mortality and the role of work: a register study of Finnish men. Int J Epidemiol. 2002;31:614-21. http://dx.doi.org/10.1093/ije/31.3.614.

12. Melamed S, Kristal-Boneh E, Froom P. Industrial Noise Exposure and Risk Factors for Cardiovascular Disease: Findings from the CORDIS Study. Noise Health.1999;1:49-56.

13. Stansfeld SA, Matheson MP. Noise pollution: non-auditory effects on health. Br Med Bull. 2003;68:243-57. http://dx.doi. org $/ 10.1093 / \mathrm{bmb} / \operatorname{ldg} 033$. 
14. Babisch W. Stress hormones in the research on cardiovascular effects of noise. Noise Health. 2003;5:1-11.

15. McEwen BS, Wingfield JC. The concept of allostasis in biology and biomedicine. Horm Behav. 2003;43:2-15. http://dx.doi. org/10.1016/S0018-506X(02)00024-7.

16. van Kempen EE, Kruize H, Boshuizen HC, Ameling CB, Staatsen BA, de Hollander AE. The association between noise exposure and blood pressure and ischemic heart disease: a meta-analysis. Environ Health Perspect. 2002;110:307-17. http:// dx.doi.org/10.1289/ehp.02110307.

17. Brunner EJ, Hemingway H, Walker BR, Page M, Clarke P, Juneja M, Shipley MJ, Kumari M, Andrew R, Seckl JR, et al. Adrenocortical, autonomic, and inflammatory causes of the metabolic syndrome: nested case-control study. Circulation. 2002;106:2659-65. http://dx.doi.org/10.1161/01.CIR.0000038364.26310.BD.

18. Macleod J, Davey SG, Heslop P, Metcalfe C, Carroll D, Hart C. Limitations of adjustment for reporting tendency in observational studies of stress and self reported coronary heart disease. J Epidemiol Community Health. 2002;56:76-7. http://dx.doi.org/10.1136/jech.56.1.76.

19. Bonde JP, Munch-Hansen T, Agerbo E, Suadicani P, Wieclaw J, Westergaard-Nielsen N. Job strain and ischemic heart disease: a prospective study using a new approach for exposure assessment. J Occup Environ Med. 2009;51:732-8. http:// dx.doi.org/10.1097/JOM.0b013e3181a826f6.

20. Steenland K, Johnson J, Nowlin S. A follow-up study of job strain and heart disease among males in the NHANES1 population. Am J Ind Med. 1997;31:256-60. http://dx.doi.org/10.1002/(SICI)1097-0274(199702)31:2<256::AIDAJIM16>3.0.CO;2-0.

21. Kasl SV. The influence of the work environment on cardiovascular health: a historical, conceptual, and methodological perspective. J Occup Health Psychol. 1996;1:42-56. http://dx.doi.org/10.1037/1076-8998.1.1.42.

22. Babisch W, Fromme H, Beyer A, Ising H. Increased catecholamine levels in urine in subjects exposed to road traffic noise: the role of stress hormones in noise research. Environ Int. 2001;26:475-81. http://dx.doi.org/10.1016/S01604120(01)00030-7.

23. McEwen BS, Stellar E. Stress and the individual. Mechanisms leading to disease. Arch Intern Med. 1993;153:2093-101. http://dx.doi.org/10.1001/archinte.153.18.2093.

24. Chandola T, Heraclides A, Kumari M. Psychophysiological biomarkers of workplace stressors. Neurosci Biobehav Rev. 2010;35:51-7. http://dx.doi.org/10.1016/j.neubiorev.2009.11.005.

25. Babisch W. Cardiovascular effects of noise. Noise Health. 2011;13:201-4. http://dx.doi.org/10.4103/1463-1741.80148.

26. Fogari R, Zoppi A, Corradi L, Marasi G, Vanasia A, Zanchetti A. Transient but not sustained blood pressure increments by occupational noise. An ambulatory blood pressure measurement study. J Hypertens. 2001;19:1021-7. http://dx.doi. org/10.1097/00004872-200106000-00005.

Jens Peter Bonde, MD

Department of Occupational

and Environmental Medicine,

Bispebjerg Hospital,

University of Copenhagen, Denmark

[E-mail:.jpb@bbh.regionh.dk]
Henrik A Kolstad, MD

Danish Ramazzini Centre,

Department of Occupational Medicine,

University of Aarhus, Denmark

[E-mail: henkols@rm.dk] 
